\title{
LI. Magnetism of basalt
}

\section{G.E. Allan D.Sc.}

To cite this article: G.E. Allan D.Sc. (1909) LI. Magnetism of basalt , Philosophical Magazine Series 6, 17:100, 572-581, DOI: 10.1080/14786440408636631

To link to this article: http://dx.doi.org/10.1080/14786440408636631

$$
\text { 册 Published online: } 21 \text { Apr } 2009 .
$$

Submit your article to this journal 전

\section{Article views: 4}

Q View related articles $\longleftarrow$

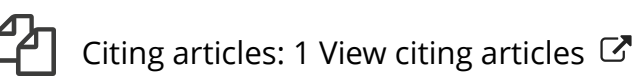


even when the surface-layers become saturated, so that the solute separates out in a solid form.

The results of these experiments do not support this view. In the first place, the rate of surface separation varies in an irregular manner quite inconsistent with the above theory. Secondly, there is no sign of equilibrimm even after a prolonged period. Thirdly, this theory does not explain the initial thickening and subsequent thinning of the surfacelayer, which occurs in the case of strong solutions of peptone and albumin.

The results indicate that the process is of a much more complex character than simple "capillary-osmotic" action. It is possible that the substance of the surface-layer differs chemically from the original solute. This view was put forward by Metcalf* as the result of experiments on surfacefilms formed by allowing a drop of peptone solution to spread over a water surface. At present I am engaged on a series of experiments on surface-layers formed at the interface between solutions of saponine, peptone, and albumin, and hydrocarbon oils. This case, though more difficult to investigate practically, possesses theoretical advantages due to the absence of evaporation and chemical action between the two media.

The University, Leeds.

Dec. 2lst, 1908.

LI. Magnetism of Basalt. By G. E. AluaN, D.Sc., Lecturer on Electricity, Pure and Applied, and Assistant to the Professor of Natural J'hilosophy, in the Univer'sity of Glasgow $\dagger$.

$\mathrm{T}$ a previous paper $\ddagger$ it was shown that bars of basalt 1 heated in air undergo a magnetic change, partly temporary and partly permanent. In general the permanent effect consists in a loss of magnetic susceptibility. Some instances of an increase have, however, been observed. The temporary effect is, roughly, similar to that in magnetite; the bar reaches a state of maximum strength, which is followed by a state of minimum strength at a temperature which is not the same for all, but is, for the majority of cases examined, in the neighbourhood of $600^{\circ} \mathrm{C}$.

In order to obtain further information as to the behaviour of such material, tests were carried out on new bars of

* Zeit. für Phys. Chem. vol. lii. p. 1 (1905).

+ Comnunicated by Professor A. Gray, F.R.S.

$\ddagger$ Phil. Nag. January 1904, p. 45. 
basaltic rock, and on bars of magnetite, ilm»nite, and hæmatite ore.

It is proposed to give here the particulars obtained for basalt. Five new bars were cut from specimens obtained in the following localities:-

1. Top of Sgurr nan Gillean, Skye.

2. The Storr Mountain, Skye.

3. Dunvegan district, Skye.

4. Stacks of Netherton, a basaltic * dyke in the sea near Stromness, Orkney.

5. Faule Ader, Dattenberg, a vein of non-columnar basalt which passes roughly across the middle of the Dattenberg quarry, near Linz, on the Rhine.

\section{Method.}

As in the previous research, the magnetometric method was employed, certain modifications having been introduced from time to time. The quartz-fibre suspension was replaced by a single silk tibre which has been found to work very satisfactorily. The length of the needle was reduced from $1 \mathrm{~cm}$. to $25 \mathrm{~cm}$. A platinum thermometer was employed in the measurement of temperature at first, but was replaced during the course of the experiments by a thermo-electric couple which was standardized in ice, steam, mercury-vapour, and molten aluminium.

\section{Method of Compensation.}

A few remarks may be made here on the compensation of the magnetizing coil. In making magnetometer observations with weakly magnetic material, such as basalt or Heusler's alloy, the specimen requires to be near the needle in order to cause a suitable deflexion. Erhard $\dagger$ has pointed out that with such a disposition, any slight deviation of the axes of the magnetizing and compensating coils from the magnetic east and west line gives rise to a component along the meridian which, for one direction of the magnetizing current, increases the directive force $\mathrm{H}$, and for the opposite direction diminishes it. Erhard has also shown that the presence of this effect may be tested by first compensating for the zero position, and then deflecting the needle with a bar-magnet

* The geological nature of this rock is described by J. S. Flett in "The Trap Dykes of the Orkneys," Trans. Roy. Soc. Edin. vol. xxxix. p. 865 .

† T. Erhard, Ann. d. Physiz [4] vol. ix. p. 724 (1902). 
and testing the compensation in the new position of the needle.

The presence of these $\mathrm{H}$-disturbing components may be more easily tested and their magnitude gauged by timing the period of oscillation of the needle with no current, and with direct and reversed currents in the magnetizing and compensating coils after compensation has been made in the usual way.

This methol was used in the previous work, and indicated a change in the value of the horizontal field at the needle of over 5 per cent. when the inagnetizing current was reversed.

The effect was neutralized in the later experiments by the addition to the magnetizing-coil circuit of a small auxiliary compensating coil. The latter consisted of seven turns of wire $9 \mathrm{cms}$. in diameter, and was placed to the north of the needle at about $20 \mathrm{cms}$. distance, with its axis in the meridian through the needle. The coil was in series with the magnetizing and compensating coils, and the current was passed through it in such a direction as to neutralize forces introduced by a want of alignment of the coils of the nature shown in fig. 1 .

Fig. 1.

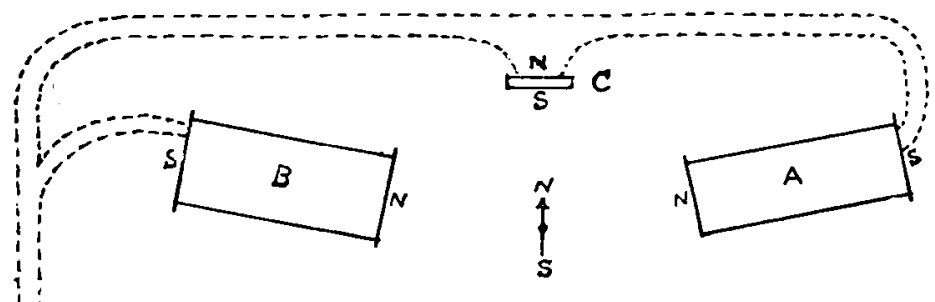

$A$ is the magnetizing coil ; $B$, the compensating coil ; and $C$ the swall auxilinry compensating coì.

A position of the coil C (fig. 1) was found such that no change took place in the period of the needle when the magnetizing current was reversed. One coil was found to be sufficient to overcome the disturbing effect, and when adjusted the compensation was good at all parts of the scale, the variation of the field-intensity being reduced to less than 0.5 per cent.

\section{The Basalt Bars.}

A preliminary examination of the five new lars was made as to their permanent magnetism, and the bars, when placed 
successively with near ends $26.75 \mathrm{cms}$. from the magnetometer needle, gave deflexions as noted below on reversal of their positions.

The relative susceptibility of the bars was also tested in a field of 40 c.c.s. units, the deflexions noted being those obtained by reversing the field.

TABLE 1.

\begin{tabular}{|c|c|c|}
\hline Bir. & $\begin{array}{c}\text { Deflexion due } \\
\text { to permanent } \\
\text { magnetism. }\end{array}$ & $\begin{array}{l}\text { Defiexion in } \\
\text { reversed field } \\
\text { of } 40 \text { c.G.s. }\end{array}$ \\
\hline Sgurr nan Gillean & $\underset{61 \cdot 3}{\mathrm{~mm}}$ & $\underset{20 \cdot 1}{\mathrm{~mm}}$ \\
\hline Storr ......... & $8 \cdot 0$ & $27 \cdot 1$ \\
\hline Dunvegan ..... & $7 \cdot 0$ & $14 \cdot 8$ \\
\hline Stromness Dyke ..... & 0 & $45 \cdot 8$ \\
\hline Faule Ader $\quad . . . . . . . .$. & 0 & $3 \cdot 3$ \\
\hline
\end{tabular}

A comparison of the two columns shows that whilst the three Skye specimens are of medium susceptibility, the Sgurr nan Gillean bar is, for rock material, very highly magnetized; the Stromness bar is composed of a material of relatively high susceptibility, and the Faule Ader bar is almost nonmagnetic.

\section{Rock Sections.}

Thin sections of the rocks Sgurr nan Gillean, Stromness Dyke, and Faule Ader were examined, and all three were found to contain crystals of magnetite as their chief magnetic constituent uniformly dispersed throughout the sections; in the section of Faule Ader the linear dimensions of the magnetite crystals were about a sixth of those of the crystals in the other two sections. Further than this, an examination of the sections in the microscope gives no clue to the widely different magnetic behaviour of these three rock specimens.

\section{Temperature Effect.}

The bars were next tested in the electric furnace in the manner previously described, and curves were obtained which, although exhibiting peculiarities, have a resemblance to the temperature-permeability curve for magnetite, and those for 
Sgtrr wan Gillean Basalt.

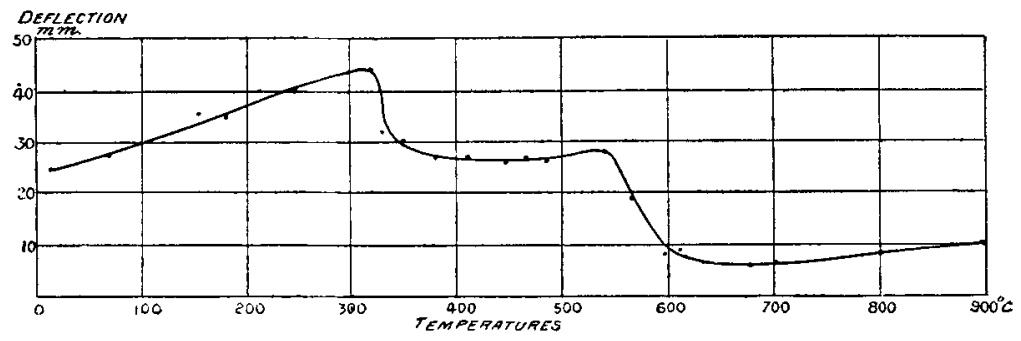

Storr Basalt.

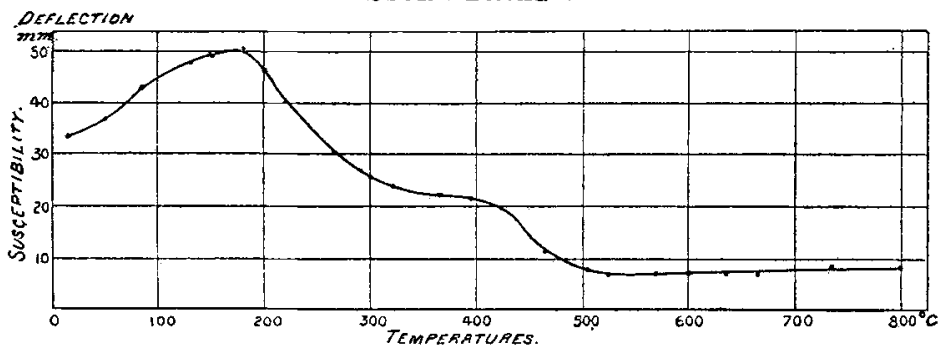

Stromnass Basalt.

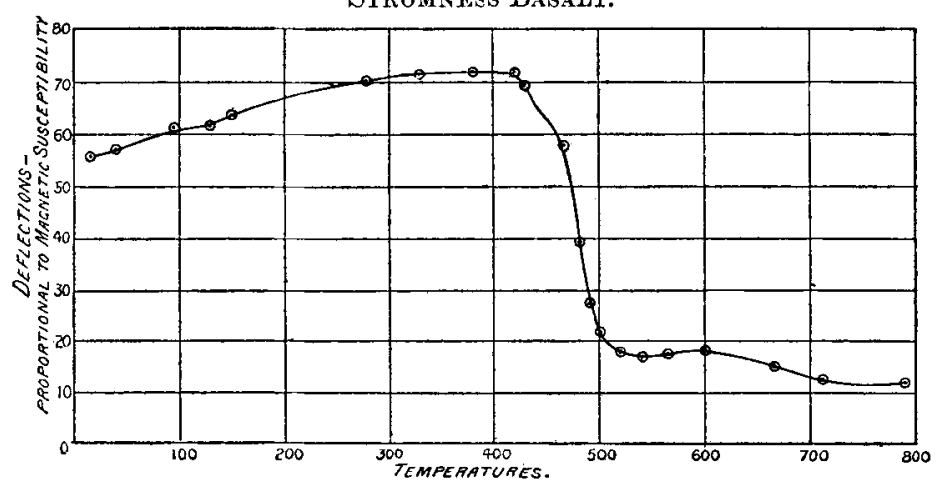

Faule Ader No. 1. First heating. $\odot \odot \odot$ Cooling curve.

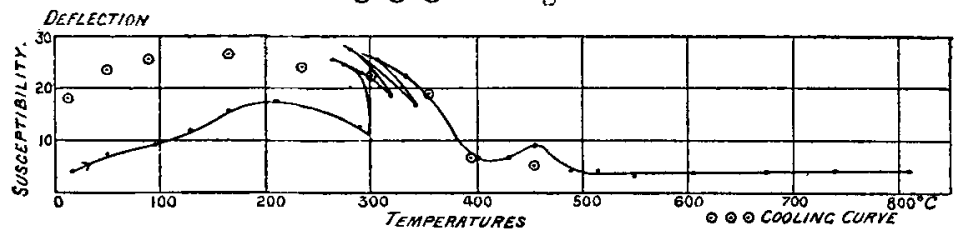


the Sgurr nan Gillean and Storr specimens have a marked resemblance to the temperature curve found for magnetite by Barton and Williams*. Curves are given for all the bars except Dunvegan, which is similar to that found for the Storr bar. In character they appear to be modifications or combinations of two types, one the curve for magnetite $\uparrow$, to which that for the Stromness bar has the greatest similarity, and second, the curves IX., X., and XII. $\dagger$ for Dattenberg bars. In the one type there is a gradual increase of susceptibility up to about $500^{\circ} \mathrm{C}$., followed by a rapid descent to a state of minimum susceptibility; in the second type the maximum susceptibility is reached at a comparatively low temperature, and this is followed by a gradual loss of power as the temperature rises. Whether the change exhibited in these curves between the temperatures of $15^{\circ}$ and $550^{\circ}$ is due entirely to the appearance of a new magnetic constituent as a result of chemical change, or to the effect of change of internal stress, is a point which cannot be decided at present. The temperature of minimum susceptibility had values for the five bars ranging from $430^{\circ}$ for the Dunvegan bar to $710^{\circ}$ for the Stromness bar, the average being about $565^{\circ} \mathrm{C}$. The temperature curve for the Faule Ader bar may be noted as one in which a large increase of susceptibility took place during heating.

To confirm the effect found in this bar an irregular strip of rock from the same block was roughly ground to pass into the furnace, and was heated to $350^{\circ} \mathrm{C}$. or thereby, and again cooled. Initially the bar had no observable magnetization, and gave a deflexion of $2 \mathrm{~mm}$. in a reversed field of 35 c.G.s. units. On being cooled, the bar now gave a deflexion of $6.5 \mathrm{~mm}$. in the same field as before, and was now magnetized so as to be capable of affecting a pocket compass. Further heatings appeared to increase the effect slightly.

After the beating of the bars, they were tested under the same conditions as those given in Table I., and the following deflexions were noted (p. 578):-

* B. A. Report, 1892.

+ See previous paper.

Phil. Mag. S. 6. Vol. 17. No. 100. April 1909. 
TABLE II. (June 15-22, 1906).

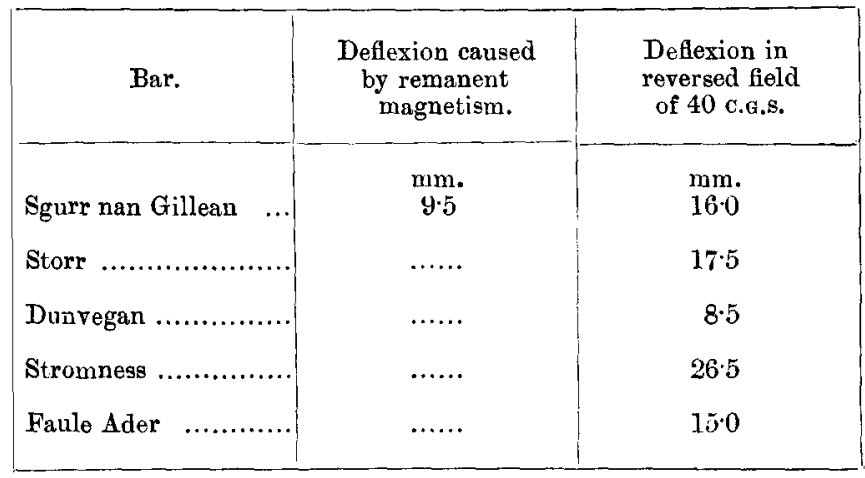

On being tested about two and a half years after the date on which the above observations were made, it was found that all the bars had lost power, as shown in the next table.

TAble III. (Nov. 11-12, 1908).

\begin{tabular}{|c|c|c|}
\hline Bar. & $\begin{array}{c}\text { Deflexion eaused } \\
\text { by remanent } \\
\text { magnetism. }\end{array}$ & $\begin{array}{l}\text { Deflexion in } \\
\text { reversed field } \\
\text { of } 40 \text { c.a.s. }\end{array}$ \\
\hline Sgurr nan Gillean ... & $\underset{87}{\mathrm{~mm}}$ & $\begin{array}{l}\mathrm{mm}_{12} \\
\text {. }\end{array}$ \\
\hline Storr $\ldots \ldots \ldots \ldots \ldots \ldots$ & $2 \cdot 3$ & $15 \cdot 7$ \\
\hline Dunvegan ... & $1 \cdot 2$ & $8 \cdot 1$ \\
\hline Stromness ............... & $5 \cdot 2$ & $20 \cdot 9$ \\
\hline Faule Ader ... & $2 \cdot 9$ & $11 \cdot 6$ \\
\hline
\end{tabular}

The loss of susceptibility amounts to from 45 to 61 per cent. in the first four bars, and the increase of susceptibility in the fifth bar brings it almost to an equality with that of the first bar.

\section{Effect of Baking and Cooling.}

To test whether change of temperature alone could do anything to restore or increase the magnetic quality of basalt, the processes of baking in hydrogen and cooling in liquid air were tried on two bars. 
The bar from Sgurr nan Gillean was heated at about $400^{\circ} \mathrm{C}$. in a current of hydrogen for various periods, amounting in all to four hours. The total result was to further diminish the magnetic power of the bar, the deflexion caused by remanent magnetism being reduced from 9.5 to $8.7 \mathrm{~mm}$. (see Tables II. and III.).

The temperature of one of the Dattenberg bars was reduced by means of liquid air, and the deflexions were noted which it produced when a field of 60 c.(4.s. was reversed, no readings of temperature being taken. The low temperature diminished the susceptibility of the bar to one half its value at ordinary temperature, the bar slowly regaining its former condition as the temperature rose. This behaviour is different from that observed in other materials, e. g., a bar of ilmenite became temporarily 1.2 times stronger in liquid air; a bar of magnetite exhibited a slight increase, also temporary in nature; and a bar of Heusler alloy became 1.2 times stronger than before, the change this time being permanent.

\section{Average Composition and Probable Average Susceptibility of Basalt.}

From a series of eight basalts chosen for me by Professor W. W. Watts from Roth's 'Petrography' as giving average analyses, it is found that in these the average content of iron is 6.1 per cent. $\dddot{\mathrm{F}}$, or iron in the form of $\mathrm{Fe}_{2} \mathrm{O}_{3}$, and 5.9 per cent. $\dot{F e}$, or iron in the form $\mathrm{FeO}$, these two forms varying in quantity in the eight basalts, the $\dddot{F}$ e from 16.4 per cent. to zero, and the Fe from $11 \cdot 6$ per cent to zero.

Now if we assume that basalt contains, on an average, 12 per cent. by weight of magnetite, and the average weight of the basalt bars employed is 65 gms., the weight of magnetite contained in the bar is $\frac{12}{100} \times 65$ or $7.8 \mathrm{gms}$. The density of magnetite is $5 \cdot 2$, and therefore its volume is $\frac{7 \cdot 8}{5 \cdot 2}$ or 1.5 c.cs. Since the average volume of the bar is 22 c.cs. $\frac{1 \cdot 5}{22}$ of that volume, or 7 per cent., is magnetite. Now, if we consider the susceptibility of magnetite to vary from $\cdot 15$ to $\cdot 75^{*}$, the susceptibility of basalt, if taken as

* Roughly the values found for two bars of magnetite. The former of the two values was erroneously stated in the previous paper as 016 instead of $0 \cdot 16$.

\section{$2 \mathrm{R} 2$}


proportional to the quantity of magnetite contained, should lie between $\cdot 01$ and $\cdot 05$. But, since half the iron is present as $\mathrm{Fe}_{2} \mathrm{O}_{3}$, the non-magnetic oxide, the lower limit should be reduced to 005 , the upper limit being retained, since heat may change the ferric oxide into magnetic oxide. Hence, on the average, and if we neglect demagnetizing action, the susceptikility of basalt should lie between $\cdot 005$ and $\cdot 05$. The values found by Ruicker and White* lie between .0003 and $\cdot 0139$, the average value for specimens of basalt found within the British Isles being 0026 . The above average limits, therefore, seem to be rather high, but the average susceptibility of the nine bars mentioned in the previous paper is .0046 , and that of the Stromness bar is $\cdot 033$.

\section{Effect of Hcematite.}

In its main features the magnetic behaviour of basalt resembles that of magnetite; but there are cases in which another substance plays a part, as in that of the Faule Ader bar (Curve 4). Folgheraiter $\dagger$ has described another instance in which unbaked, ferruginous, non-magnetic clay was heated to a dull red heat, and became noticeably magnetized by the earth's field on cooling. These results seem to point to the sesquioxide of iron-otherwise known as ferric oxide, hæmatite, and $\mathrm{Fe}_{2} \mathrm{O}_{3}$ - as being a possible factor of disturbance in the cases mentioned. Moissan $\ddagger$ has stated that the sesquioxide of iron, when heated in an atmosphere of hydrogen or carbonic acid at a temperature between $350^{\circ}$ and $440^{\circ} \mathrm{C}$., changes in a few hours into the magnetic oxide $\mathrm{Fe}_{3} \mathrm{O}_{4}$, the new compound being an allotropic form of the ordinary magnetic oxide, and differing from it in density and in other particulars. It is distinctly probable that this change of non-magnetic sesquioxide into the magnetic oxide at about $400^{\circ} \mathrm{C}$. may be the cause of the peculiar changes observed, and that this: change constitutes an important factor, though an uncertain one, in questions of terrestrial magnetism. Further, it offers another means of explaining the presence of strong magnetization in surface rocks, other than that which attributes it solely to the magnetizing effect of a lightning flash. Pockels $\S$ employs the observed intensity of magnetization in his basalt bars to calculate the magnetizing lightning current

* Rücker and White, Proc. R. S. lxiii. p. 460 (1898).

+ Science Abstracts, No. 414, 1898.

† H. Moissan, Comptes Rendus, lxxxvi. p. 600 (1878).

§ F. Pockels, Ann. d. Physik, lxiii. p. 195 (1897). 
at 10,000 amperes, which he considers a low estimate. The effect of the lightning may be partly a heating one, the rock being heated so far as to transform a non-magnetic into a magnetic constituent, which is then magnetized by the earth's field. A second possibility is to attribute the chemical change to the sun's heat, and the magnetization to the lightning flash, since the experiments of Folgheraiter and Messrs. Platania* have proved that both the earth's field and lightning are operative in producing magnetization in rock material.

Experiments on hæmatite ores are in progress, but sufficient has been done to find that the second allotropic form of magnetite, into which they change on being heated at $400^{\circ}$, behaves similarly to the more common form as regards loss of magnetic power about $550^{\circ} \mathrm{C}$.

The experiments described in this paper were made in the Natural Philosophy Buildings of Glasgow University, and I have to thank Professor Gray for valuable suggestions made during their progress.

Glasgow, 30 Nov. 1908.

LII. The Secondary Spectrum of Hydrogen. $B y$ C. F. Hoglex, A.R.C.Sc., B.Sc.†

$\mathrm{T} T$ is well known that vacuum-tubes filled with hydrogen 1 emit two spectra. One of these consists of the wellknown lines which are seen reversed in the spectrum of the sun and in the spectra of some stars. The other spectrum is known as the secondary spectrum, and consists of a multitude of fine lines crowding the visible region, being especially conspicuons in the neighbourbood of the yellow. These lines have not been observed in stellar or solar spectra, and it has been regarded as doubtful whether they are due to hydrogen at all.

It seems almost certain that if this spectrum is not due to hydrogen, it is due to some more easily condensible substance. Sir James Dewar has shown that all gases except hydrogen, neon, and helium, are readily condensed by charcoal at the temperature of liquid air. This method of condensation seems to afford an opportunity of testing whether or not the secondary spectrum is in reality due to hydrogen.

* G. \& G. Platania, Comptes Rendus, cxli. p. 974 (1905).

+ Communicated by the Hon. R. J. Strutt, F.R.S. 